\title{
A Study of Coal Miners' Safety Psychological Elements Based on Questionnaire Survey
}

\author{
Zeng-bo Li $^{1,2}$, Long-kang Wang ${ }^{1,2}$, Dong Zhang ${ }^{1,2}$, Bin Peng ${ }^{1,2}$, Jia-bin Zhang ${ }^{1,2}$, Ting Hong ${ }^{1,2}$, Han Shen ${ }^{1,2}$ and Liang \\ Dong ${ }^{1,2}$ \\ ${ }^{1}$ China University of Mining \& Technology (Beijing), School of Resources \& Safety Engineering, 100083 Beijing, China \\ ${ }^{2}$ China University of Mining \& Technology (Beijing), State Key Laboratory of Coal Resources and Safe Mining, 100083 Beijing, China
}

\begin{abstract}
During the production process, the instability of safety psychological elements of coal miners contributes to unsafe behaviors that may result in fatal accident. To search the dominant psychological elements, three types of unsafe psychology, comprising 18 unsafe psychological elements, are obtained by theoretical analysis and site survey. Then, an assessment model is established, and a matched questionnaire is applied to two large modern coal mines in Inner Mongolia Autonomous Region. Based on questionnaire survey results and analytic hierarchy process (AHP), assessment judgment matrixes are constructed, effect weight is calculated, and consistency check is conducted. The analysis results show that safety psychology elements of defective type are the dominant elements that trigger unsafe behaviors of coal miners.
\end{abstract}

\section{Introduction}

In recent years, with the increasing investment in production safety, the improving adjustment in energy structure, and the improving macroeconomic situation, Death rate per million tons of coal mines is declining year by year in China. The rate in 2012 was 0.374 , a rate lower than 0.5 for the first time in history [1]. The situation in China's coal mines keeps turning better, however, in comparison with the advanced international level, the gap is still evident. Death rate per million tons is roughly $0.02 \sim 0.03$, and even zero in some years in the developed nations. This indicates that safety situation of coal mines is still severe. Researches show that up to $80 \%$ of the coal mine accidents is the result of unsafe behaviours that are the outward manifestation of unsafe psychology. Therefore, to study the safety psychology of coal mine workers is of important theoretical and realistic significance to improve safety situation and protect their life.

\section{Establishment of Assessment Model on Safety Psychology for Coal Mine}

\subsection{Theoretical Analysis of Safety Psychology}

Safety psychology is a science that aims to minimize and eliminate accidents from the source [2]-[4] by interpreting, regulating and predicting workers' behaviours based on the law of the deeply rooted psychological activity behind behaviours. Safety psychology is an independent interdisciplinary subject on the basis of psychology and safety science. Its essence is the new application of psychology in the field of safety science [5]-[7]. Safety psychology of coalmine is a special and important research and application field of safety psychology. It aims to prevent coalmine accidents and protect life and health of coalminers [8], [9]. It is an emerging application science that investigates the occurrence of coalmine accidents and prevents the psychological elements of mankind and their exerting law by combining with the production activity law and specific practices of work safety in coal mines [10].

Investigation of the influence of the safety psychology of coalminers on their safety behaviours concentrates on their safety psychological process, which covers cognition and safety, emotion and safety, wills and safety, attention and safety. The four aspects are correlated, mutually promoted, and unified in safety psychological process [11]. At first, let us analyse cognition and safety. Safety cognition process, coalminer-oriented, is a very complicated processing course of cognition message. As the processor of message, a coalminer will, through his physiological organs like eye, nose, ear, hand and foot, receive the relevant information of the object in production process, and conduct effect information process, and thus make wise and correct information judgment and guarantee the implementation of safety behaviours [12], [13]. In China, because of the lowthreshold of coalminers' work, they have poor education background and technique competence, and lack cognition on the underground working environment, different marks and geographic environment, as a result, 
they lack cognition on the objective loopholes in work safety such as hidden dangers, have no means to do qualified jobs and cannot ensure work safety [14].

Second, let us analyse emotion and safety. Safety emotion is a kind of emotion produced in the body of coalminers in a given timeframe under the influence of a given event or scenario. Typical emotional states include mental state, passion and stress [15]. Practices show that coalminers are affected by kinds of underground severe environment such as dim light, black coal and rock, large dust concentration in workface, threat from gas explosions and coal-gas outburst. On the one hand, this circumstance make coalminers form a team unit similar to a small family where they care for and influence each other, which is good for formation of the safety psychology of coalminers. On the other hand, this circumstance creates their bad-tempered character, which is adverse to work safety, and sometimes is the direct trigger of accidents [16], [17].

Third, let us analyse wills and safety. Wills is the preparatory state of behavior. Coalminers have endurance and persistence in special underground environment. For example, a water-inrush accident, occurred in Jingyang No. 2 mine of Yiyang County of Henan Province, because of strong wills, coalminers had persisted for 21 days until they were saved by the rescuers.

At last, let us analyse attention and safety. Attention means conscious psychological activity's orientation and concentration on a given matter. Safety attention directly influences the safety behaviours of coalminers [18], [19]. Research indicates that coalminers' inattention leads to a large portion of coal mine accidents among quantities of coalmine safety accidents.

\subsection{Assessment model of safety psychology for coal mine}

The assessment model of safety psychology is designed on the basis of the theoretical analysis of coal mine safety psychology. In this model, unsafe psychological elements are divided into types of situational, defective and endogenous. The first is motive-typed where different levels of need cannot be satisfied, the second is a mental process-typed where safety cognitive ability is inadequate, emotion and feeling are confused, and attention is not concentrated, The third is a personality difference-typed based on safety character and temperament ${ }^{[20,21]}$. By analysing the unsafe psychological elements of three types, it can be found that both their generation and evolution mechanism are different (shown in Table 1), so that further analysis on countermeasures should be conducted.

In the assessment model of safety psychology, the three unsafe psychological types include numerous safe psychological elements. The elements mean the psychological factors of coalmines which change under external environments such as the nature, society, coal mine enterprises, family and operating environment, and their own physiological and psychological fluctuations in the production process. Through theoretical research, site survey and statistical analysis, it is concluded that there are 18 safety psychological elements that influence the safety behaviours of coalminers. They include carelessness, emotion flaw, inertial violation, inadequate cognitive level, conformity, poor safety awareness, safety character, stress state, risky mind, safety temperament, reversal mind, lack of experience, over fatigue, safety need, boredom, poor environment, distraction, biorhythm, etc. The assessment model of safety psychology is as shown in Fig. 1.

Table 1. Types of unsafe psychological elements and their features.

\begin{tabular}{|c|c|c|c|}
\hline Type & $\begin{array}{l}\text { Generation } \\
\text { mechanism }\end{array}$ & Stability & Actor \\
\hline Situational & $\begin{array}{l}\text { Triggered by } \\
\text { external cause }\end{array}$ & $\begin{array}{l}\text { Apt to } \\
\text { change }\end{array}$ & Third party \\
\hline Defective & $\begin{array}{c}\text { Internal and } \\
\text { external } \\
\text { influence }\end{array}$ & $\begin{array}{l}\text { Change } \\
\text { after } \\
\text { efforts }\end{array}$ & $\begin{array}{l}\text { Object affects } \\
\text { subject to act }\end{array}$ \\
\hline Endogenous & $\begin{array}{l}\text { Determined by } \\
\text { internal cause }\end{array}$ & $\begin{array}{l}\text { Hard to } \\
\text { change }\end{array}$ & To guide \\
\hline
\end{tabular}

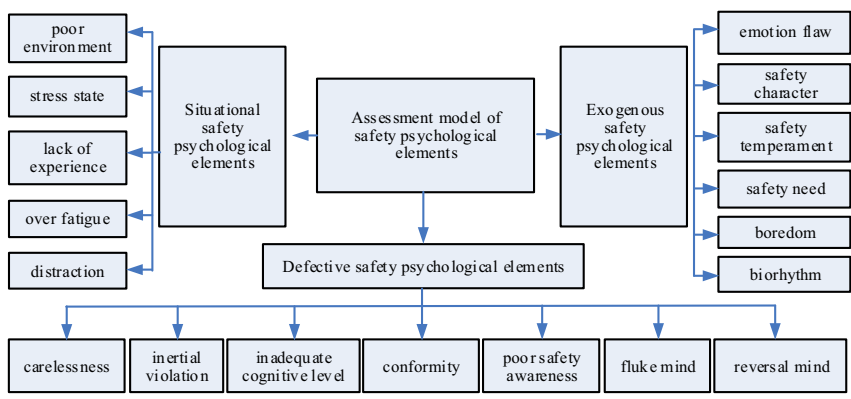

Figure 1. Assessment model of safety psychological elements.

\section{Design of survey questionnaire and survey analysis}

\subsection{Design and implementation of survey questionnaire}

Design of survey questionnaire is unfolded from the theoretical analysis of coal mine safety psychology and the assessment model of safety psychological elements. Based on this, experts are interviewed in coal mine industry. A preliminary survey questionnaire on coalminers' safety psychology is designed. Then, small scale test is made, the insufficiencies are found and improved. 32 questions are defined for survey questionnaire that cover 18 safety psychological elements, where 11 questions on situational type, 11 questions on defective type, and 10 questions on endogenous type.

After the survey questionnaire is well-designed, the staffers of Inner Mongolia Zhongbei Coal Chemicals Company (Zhongbei) and Inner Mongolia Dongdaneng Mining Co. Ltd. (Dongdaneng) serve as the assessed subjects. The controlling party of Zhongbei is a stateowned enterprise, and its management system can representatively embody the current state of the central government-owned enterprises and other state-owned enterprises in Inner Mongolia, while Dongdaneng is one of privately-run enterprises in the region which are the largest in scale and best in economic benefits, and its 
management system can fully embody local and private enterprises.

The implementation of questionnaire survey takes into account sampling method and survey mode. Probability sampling method is selected for the survey. Probability sampling comprises stratified sampling, cluster sampling, random sampling, etc. Errors can be calculated. This can better avoid errors in sampling and coverage. In the implementation process, a large sample database is established at first, then a survey is conducted by probability sampling. Prior to implementation of the survey questionnaire, the purpose was explained to the coalminers, and the coal mine officials were requested to lead in the survey. Then, coalminers were asked to complete the questionnaire. The timeframe of completing the questionnaire was regulated. Finally, the contact information of the respondents was left on each questionnaire for later interviews and improvement of survey information.

\subsection{Analysis of questionnaire survey}

Through arrangement and statistics of the survey questionnaires, it is concluded that the scores of safety psychological elements of Zhongbei's coal mines are higher than Dongdaneng's. Moreover, the higher the academic degree, the more stable safety psychological quality, so is the position. However, among situational, defective and exogenous safety psychological elements, it is hard to determine the major element that triggers unsafe behaviours of coalminers. Therefore, analytical hierarchy process (AHP) is adopted to determine the weight of safety psychological elements. The purpose is to decide what safety psychological element exerts the most influence on the coalminers. AHP consists of construction of judgment matrix, calculation of weight and consistency check.

\subsubsection{Construction of judgment matrix}

As illustrated in Figure 1, the assessment model of safety psychological elements is a hierarchical-structured model. The target layer is the assessment result of safety psychological elements (A). The criterion layer is the safety psychological elements of Situational, Defective and Endogenous, set as $B_{1}, B_{2}$ and $B_{3}$, respectively. The grade-II influential factors of Situational safety psychological elements $\left(\mathrm{B}_{1}\right)$ include poor environment, stress state, lack of experience, over fatigue $\left(B_{14}\right)$ and distraction $\left(\mathrm{B}_{15}\right)$. The grade-II influential factors of Defective safety psychological elements $\left(B_{2}\right)$ include carelessness $\left(\mathrm{B}_{21}\right)$, inertial violation $\left(\mathrm{B}_{22}\right)$, inadequate cognitive ability $\left(\mathrm{B}_{23}\right)$, conformity $\left(\mathrm{B}_{24}\right)$, poor safety awareness $\left(\mathrm{B}_{25}\right)$, fluke mind $\left(\mathrm{B}_{26}\right)$ and reversal mind $\left(\mathrm{B}_{27}\right)$. Grade-II influential factors of Endogenous safety psychological elements $\left(\mathrm{B}_{3}\right)$ include emotion flaw $\left(\mathrm{B}_{31}\right)$, safety character $\left(B_{32}\right)$, safety temperament $\left(B_{33}\right)$, safety need $\left(\mathrm{B}_{34}\right)$, boredom $\left(\mathrm{B}_{35}\right)$ and biorhythm $\left(\mathrm{B}_{36}\right)$.

By use of paired comparison method, the safety psychological elements in the three types are scored in pairwise comparison to construct judgment matrix A. 9- level scoring method is used for assessment criteria. Scoring criteria are shown in Table 2. In the judgment matrix A, if element $i$ is compared with element $j$, its importance is $a_{i j}$, the ratio of representation between element $j$ and element $i$ is $a_{i j}=1 / a_{i j}$.

Table 2. Meanings of AHP scores.

\begin{tabular}{cl}
\hline Score & \multicolumn{1}{c}{ Meaning } \\
\hline 1 & Two elements are equally important. \\
\hline 3 & Former element is slightly important than latter one. \\
\hline 5 & Former element is more important than the latter one. \\
\hline 7 & $\begin{array}{l}\text { Former element is significantly important than latter } \\
\text { one. }\end{array}$ \\
\hline 9 & Former element is absolutely important than latter one. \\
\hline $2,4,6,8$ & The mean value of the above adjacent judgments \\
\hline
\end{tabular}

The data of Zhongbei was processed. In order to overcome the influence of subjective factors on AHP results to the largest extent, the mean scores of 100 samples in situational, defective and endogenous were analyzed, and pairwise comparison was done. By giving quotients and differences and amplifying appropriate multiples, they were made to accord with the requirements of 9-level scoring method. The results are as shown in Table 3. In like manner, the data of 100 samples of Dongdaneng were calculated. The results are as shown in Table 4.

Table 3. Matrix of pairwise judgment for three safety psychological types in Zhongbei.

\begin{tabular}{cccc}
\hline $\begin{array}{c}\text { Assessment result } \\
(\mathrm{A})\end{array}$ & $\begin{array}{c}\text { Situational } \\
\left(\mathrm{B}_{1}\right)\end{array}$ & $\begin{array}{c}\text { Defective } \\
\left(\mathrm{B}_{2}\right)\end{array}$ & $\begin{array}{c}\text { Endogenous } \\
\left(\mathrm{B}_{3}\right)\end{array}$ \\
\hline Situational $\left(\mathrm{B}_{1}\right)$ & 1 & $1 / 4$ & $1 / 3$ \\
Defective $\left(\mathrm{B}_{2}\right)$ & 4 & 1 & 2 \\
Endogenous $\left(\mathrm{B}_{3}\right)$ & 3 & $1 / 2$ & 1 \\
\hline
\end{tabular}

Table 4. Matrix of pairwise judgment for three safety psychological types in Dongdaneng.

\begin{tabular}{cccc}
\hline $\begin{array}{c}\text { Assessment result } \\
(\mathrm{A})\end{array}$ & $\begin{array}{c}\text { Situational } \\
\left(\mathrm{B}_{1}\right)\end{array}$ & $\begin{array}{c}\text { Defective } \\
\left(\mathrm{B}_{2}\right)\end{array}$ & $\begin{array}{c}\text { Endogenous } \\
\left(\mathrm{B}_{3}\right)\end{array}$ \\
\hline Situational $\left(\mathrm{B}_{1}\right)$ & 1 & $1 / 2$ & 3 \\
Defective $\left(\mathrm{B}_{2}\right)$ & 2 & 1 & 5 \\
Endogenous $\left(\mathrm{B}_{3}\right)$ & $1 / 3$ & $1 / 5$ & 1 \\
\hline
\end{tabular}

\subsubsection{Calculation of weight}

Matrix A obtained from Table 3 is just the judgment of AHP. Generally, the eigenvector of the largest characteristic root is considered as weight vector. The weight vector is just the weight index of the elements of this layer in respect to a factor of its upper layer. At first, each column of the judgment matrix $\mathrm{A}$ is normalized, namely,

$$
B_{i j}=\left\{B_{i j} / \sum_{i=1, j=1}^{3} B_{i j}\right\}, i=1,2,3, j=1,2,3
$$

Normalized judgment matrix B is obtained. Matrix B is added by row, namely 


$$
W_{i}=\sum_{j=1}^{4} B_{i j}, \quad i=1,2,3
$$

Hence weight $\beta=\left[\beta_{1}, \beta_{2}, \beta_{3}\right]$ is figured out, where $\beta_{i}=W_{i} / \sum W_{i}, i=1,2,3$.

\subsubsection{Consistency check}

In order to assess the reasonable degree of the judgment matrix, it is needed to make consistency check for the matrix. After the weight is obtained, the largest eigenvector of the matrix $\mathrm{A}$ is attained.

$$
\lambda_{\max }=\frac{1}{n}\left(\sum_{i=1}^{3}(A \times W)_{i} / W_{i}\right)
$$

where, $\lambda_{\max }$ is the largest characteristic root of matrix A; $n$ is the number of factors; $W_{i}$ is the weight of factor $i$. The values of $\lambda_{\max }$ and $W_{\mathrm{i}}$ are shown in Table 5 .

Table 5. Values of $\lambda_{\max }$ and $W_{\mathrm{i}}$.

\begin{tabular}{ccccc}
\hline & $\lambda_{\max }$ & $\boldsymbol{W}_{\mathbf{1}}$ & $\boldsymbol{W}_{\mathbf{2}}$ & $\boldsymbol{W}_{\mathbf{3}}$ \\
\hline Zhongbei & 3.0183 & 0.1220 & 0.5584 & 0.3196 \\
Dongdaneng & 3.0037 & 0.3090 & 0.5819 & 0.1095 \\
\hline
\end{tabular}

Then consistency index is

$$
C I=\left(\lambda_{\max }-n\right) /(n-1)
$$

According to the value of the average random consistency index $R I$ of same order matrix as shown in Table $6,3^{\text {rd }}$ order matrix's $=0.52$. Then consistency ratio $C R$ is calculated with formula 5

$$
C R=C I / R I
$$

Table 6. Values of average random consistency index $R I$.

\begin{tabular}{ccccccc}
\hline Order & 2 & 3 & 4 & 5 & 6 & 7 \\
\hline $\boldsymbol{R I}$ & 0 & 0.52 & 0.89 & 1.12 & 1.26 & 1.36 \\
\hline Order & 8 & 9 & 10 & 11 & 12 & \\
\hline $\boldsymbol{R} \boldsymbol{I}$ & 1.41 & 1.46 & 1.49 & 1.52 & 1.54 & \\
\hline
\end{tabular}

If $C R<0.1$, the consistency of the judgment matrix is acceptable. It can be known from the above calculations, $C R$ of Zhongbei's judgment matrix is 0.0176 , and $C R$ of Dongdaneng's judgment matrix is 0.0036 , both less than 0.1 . Therefore, the coefficients of the judgment matrixes shown in Table 3 and Table 4 are reasonable and acceptable.

According to Table 3 and Table 5, In Zhongbei's judgment matrix, weight coefficient of defective psychological elements is the largest, endogenous elements come second, and situational elements are in the last place. This demonstrates that, although the stateowned coal mine has higher quality coalminers and pays them well, and has better coal mining mechanization, it does not adequately train the staff on safety, and the coalminers generally have defective mind such as fluke/risk-taking mind.

According to Table 4 and Table 5, in Dongdaneng's judgment matrix, the weight coefficient of defective psychological elements is the largest, situational elements come second, and endogenous elements are in the last place. It can be seen that, whether for the state-owned coal mine or for the private-owned one, defective psychological elements are the most important factors that influence the coalminers' safety psychology. Therefore, strengthening safety training, improving safety management level and formation of sound corporate safety culture in coalmine, enterprises can effectively reduce the unsafe behaviours of coalminers, and effectively prevent safety accidents. Meanwhile, it can be noticed that, because the private-owned Dongdaneng's miners are of lower academic degree and poorer quality, and their daily work intensity is higher, situational psychological elements also significantly influence their safety psychological state, and cannot be ignored.

\section{Conclusions}

Theoretical analysis of coal mine safety psychology and thorough analysis of coalminer's safety psychological process lay a solid foundation for determining the factors of safety psychological elements.

According to the working environment of coalminers and their own condition, 18 coal mine safety psychological elements are put forward, and the assessment model and survey questionnaire for coalminer's safety psychological elements are designed.

By statistical analysis of the survey questionnaires, it is concluded that the safety psychological level of workers in state-owned coalmine is better than that of workers in private-owned coalmine; the higher the academic degree of coalminers, the longer their service life, the better their safety psychological elements. AHP analysis reveals that safety psychological elements of defective type are major factors that influence the safety behaviours of coalminers.

The questionnaire and assessment model maybe has limitation to some extent, we need explore more psychological elements based on site experience and development of safety science and psychology.

\section{References}

1. Jingchao C. Mortality rate per million tons of coal dropped to below $0.4 \%$ in 2012 [EB/OL]. http: //news.xinhuanet.com/politics/201302/07/c_124335688.htm.2013-2-7.

2. Hui S., Kaiquan W. Safety Psychology[M]. Beijing: Chemical Industry Press, 2004.

3. Edelhauser V. Psychological examination and reexamination necessity for underground worker safety[J]. Mine, petrol size, 35, 6 (1984): 284-300.

4. Whitaker Leslie A., Shoptaugh Carol F. Mine safety, productivity and job design[C]. Proceedings of the Human Factors Society 28th Annual Meeting: New Frontiers for Science and Technology, TX, USA, 1984.

5. Shichang Z. The study and exploration on the relationship between miners' psychology safety in production[C]. Proceedings of the 1998 
International Symposium on Safety Science and Technology, Beijing, China, (1998)

6. Camm T., Girard-Dwyer J. Economic consequences of mining injuries[C]. 2004 SME Annual Meeting Preprints, Denver, United states, (2004)

7. Seth Ayim G. Causal attributions of Ghanaian industrial workers for accident occurrence: Miners and non-miners perspective [J]. Journal of Safety Research, 34, 5(2003):533-538.

8. Ghosh A. K., Bhattacherjee A. Predictors of occupational injuries among coal miners: causal analysis [J]. Transactions of the Institutions of Mining and Metallurgy, 116, 1(2007):16-24.

9. Jizu L., Shaohong Z. Research on psychological evaluation system of safety personnel in coal mine $[\mathrm{C}]$. 1st International Conference on Information Science and Engineering, Nanjing, China, (2009)

10. Jizu L., Safety Psychology [M]. Beijing: China Social Guarantee of Labor Press, (2007).

11. Yajing $M$. Thinking about the safe psychological problems of the miners [J].Coal Mine Safety, 7 (2007): 87-89.

12. Yiqin Y. Miner's psychological health and coal mine safety production [J].China Coal, 4 (2000):49-51.

13. Hong C, Jing L, Ting W, et al. Regulation strategy design of coalmine management staff's psychological contract violation $[\mathrm{J}]$. Proceeded Earth and Planetary Science, 1, 1 (2009):1730-1736.

14. Theron W. J., Van Heerden G. M. J. Fatigue knowledge-a new lever in safety management $[\mathrm{J}]$.
Journal of the Southern African Institute of Mining and Metallurgy, 111, 1 (2011):1-10.

15. Lujia G. Expanding explorations of psychological methods [J]. Journal of Nanjing Normal University (Social Science), 1 (2005): 84-91.

16. Xiaojuan H., Chao W. Review on the studying methodologies of human safety psychological characteristics[J].China Safety Science Journal, 19, 7 (2009): 5-13.

17. Jizu L., Lixun K., Zhili Z., etc. Study on psychological evaluation system of safety personnel in coal mine $[\mathrm{J}]$. China Safety Science Journal, 3 (2004): 95-97.

18. Margolis K. A, Westerman C. Y. K., KowalskiTrakofler K. M. Underground mine refuge chamber expectations training: program development and evaluation[J]. Safety Science, 49, 3 (2011): 522-530.

19. Baoyue H., Fei C. Safety psychology application on coal mine safety management based on information system[C]. International Conference on Advanced Research on Electronic Commerce, Web Application, and Communication, Guangzhou, China, 2011.

20. Weimin C., Gang Z., Gang W., etc. Psychological measurement and analysis on human unsafe behavior[J]. China Safety Science Journal, 6 (2009): 29-34.

21. Guanglei $Z$. The building of psychological evaluation system and its application [J]. International Journal of Digital Content Technology and its Applications, 7, 3 (2013): 151-157. 